\title{
474385 - PERIOPERATIVE CARDIAC ARRESTS IN A SOUTHEAST ASIAN UNIVERSITY TEACHING HOSPITAL OVER FIFTEEN YEARS
}

\author{
Aliya Ahmed, FFARCSI, Mohammad Ali, FCPS, Fauzia Khan, FRCA, Mueenullah \\ Khan, FCPS \\ Anaesthesia, Aga Khan University, Karachi, Pakistan
}

Introduction: Analysis of anesthesia related complications is important to identify the preventable causes and to make prevention strategies.Studies performed in various parts of the world (1-5) have examined perioperative cardiac arrests, with the main aim of improving quality. It is important to share such data, as insight into the contribution of anesthesia to perioperative cardiac arrest in different hospitals would further increase our knowledge of the potential causes of cardiac arrests.

Methods: Local REB approval was obtained for this study. All perioperative cardiac arrests from the time of induction of anesthesia to post anesthesia care unit discharge or intensive care unit admission during noncardiac surgery, from January 1992 to December 2006 were studied. Patient's demographic information, American Society of

Anesthesiologists' physical status, type of surgery and anaesthesia were noted. Outcome variables were noted in terms of immediate and hospital survival. Anaesthesia related cardiac arrests were identified and their causes analysed.

Results: Forty two cardiac arrests occurred among 140,384 patients. Overall frequency was 2.99 per 10,000 . Twenty four (57\%) were females. Thirty four (81\%) patients belonged to ASA physical status of III - V, ten (23.8\%) were children and twenty five (59.5\%) were above 40 years. Twenty six patients (62\%) were undergoing elective surgery. Anesthesia was primarily responsible in nine cases $(0.64 / 10000)$. The causes of anesthesia related arrests were medication related (44.4\%), airway related (33.3\%), massive air embolism (11.1\%) and under-replacement of fluids (11.1\%). The event was considered to be avoidable in 26 (61.9\%) cases. Seventeen (40.5\%) patients died during the arrest, 25 survived more than one hour and ten (23.8\%) were discharged home.

Discussion: The incidence of primarily anesthesia related cardiac arrests and mortality, 0.64 per 10,000 and 0.21 per 10,000 cases respectively, was comparable with other such studies which have reported an incidence of 0.50 to 2.10 per 10,000 anesthetics for cardiac arrests $(1,5)$ and 0.12 to 1.40 per 10,000 anesthetics $(1,2,5)$ for mortality. Frequency of perioperative cardiac arrests was found to be higher in patients with poor physical status, infants, patients above 40, females and those undergoing elective surgery. Anaesthesia related cardiac arrests were mainly due to medication and airway related causes. Majority of the cases were considered avoidable indicating the importance of prevention strategies.

References: 1. Braz LG, Modolo NSP, Junior NP, Bruschi BAM, et al. Perioperative cardiac arrest: a study of 53718 anaesthetics over 9 yr from a Brazilian teaching hospital. Br J Anaesth 2006;96(5):569-75 2. Sprung J, Warner ME, Contreras MG, et al. Predictors of Survival following cardiac arrest in patients undergoing noncardiac surgery.

Anesthesiology 2003;99;259-69 3. Flick RP, Sprung J, Harrison TE, et al. Perioperative cardiac arrests in children between 1988 and 2005 at a tertiary referral centre. 
Anesthesiology 2007;106(2):226-37 4. Kopp SL, Horlocker TT, Warner ME, et al. Cardiac arrest during neuraxial anesthesia: Frequency and predisposing factors associated with survival. Anesth Analg 2005;100:855-65 5. Biboulet P, Aubas P, Dubourdieu J, Rubenovitch J, Capdevila X, D’Athis F. Fatal and non fatal cardiac arrests related to anesthesia. Can J Anesth 2001;48:326-32 